\title{
OPEN Integrative transcriptomic and gene co-expression network analysis of host responses upon Verticillium dahliae infection in Gossypium hirsutum
}

\author{
Guoli Zhang ${ }^{1,2,4}$, Zengqiang Zhao ${ }^{2,4}$, Panpan $\mathrm{Ma}^{2}$, Yanying $\mathrm{Qu}^{1}$, Guoqing Sun ${ }^{3,4} \otimes$ \\ Quanjia Chen ${ }^{1,4}$
}

Worldwide, Verticillium wilt is among the major harmful diseases in cotton production, causing substantial reduction in yields. While this disease has been extensively researched at the molecular level of the pathogen, the molecular basis of $V$. dahliae host response association is yet to be thoroughly investigated. In this study, RNA-seq analysis was carried out on $V$. dahliae infected two Gossypium hirsutum L. cultivars, Xinluzao-36 (susceptible) and Zhongzhimian-2 (disease resistant) for $0 \mathrm{~h}, 24 \mathrm{~h}, 72 \mathrm{~h}$ and $120 \mathrm{~h}$ time intervals. Statistical analysis revealed that $\mathrm{V}$. dahliae infection elicited differentially expressed gene responses in the two cotton varieties, but more intensely in the susceptible cultivar than in the resistant cultivars. Data analysis revealed 4241 differentially expressed genes (DEGs) in the LT variety across the three treatment timepoints whereas 7657 in differentially expressed genes (DEGs) in the Vd592 variety across the three treatment timepoints. Six genes were randomly selected for qPCR validation of the RNA-Seq data. Numerous genes encompassed in disease resistance and defense mechanisms were identified. Further, RNA-Seq dataset was utilized in construction of the weighted gene co-expression network and 11 hub genes were identified, that encode for different proteins associated with lignin and immune response, Auxin response factor, cell wall and vascular development, microtubule, Ascorbate transporter, Serine/threonine kinase and Immunity and drought were identified. This significant research will aid in advancing crucial knowledge on virus-host interactions and identify key genes intricate in $G$. hirsutum $L$. resistance to $V$. dahliae infection.

Cotton (Gossypium spp.) is an economically vital plant which is grown worldwide. The cotton verticillium wilt disease is a severe vascular disease which is characterized by an adverse effect on the yield of cotton and fiber quality ${ }^{1}$ with the etiological agent being the soil-borne fungus Verticillium dahliae Kleb. Wilting, yellowing, defoliation and finally death of cotton plants are caused by this fungus ${ }^{2}$, and it is difficult to monitor the pathogens as a result of their long-term survival in the soil as microsclerotia and their wide variety of hosts ${ }^{3}$.

Verticillium dahliae microsclerotia overcome soil mycostatic action and germinate to the root in existence of root exudates ${ }^{4}$. The hyphae invades host in order to establish a penetration link to the root epidermal cells through the development of an infections structure, called hyphopodium ${ }^{5}$. They penetrate the Xylem vessels and clog it, leading to a curl, necrosis, defoliation and discoloration of the leaves of the vascular tissue ${ }^{6}$. During its growth cycle, cotton is incessantly exposed to $V$. dahliae infection. Huge portions of China's cotton fields suffer from $V$. dahliae infection, and can reduce yields up to 50\%, even wiping the cultivation entirely.

To combat $V$. dahliae challenge, resistance in cotton has developed various levels of defensive mechanisms during long coexistence and arm race, including tissue structure, physiological and biochemical resistance ${ }^{7,8}$.

${ }^{1}$ College of Agriculture, Xinjiang Agricultural University, 311 Nongda East Road, Urumqi 830052, China. ${ }^{2}$ Biotechnology Research Institute, Xinjiang Academy of Agricultural and Reclamation, 221 Wuyi Highway, Shihezi, Xinjiang 832000, China. ${ }^{3}$ Biotechnology Research Institute, Chinese Academy of Agricultural Sciences, Beijing 100081, China. ${ }^{4}$ These authors contributed equally: Guoli Zhang, Zengqiang Zhao, Guoqing Sun and Quanjia Chen ${ }^{凶}$ email: sunguoqing02@caas.cn; chqjia@126.com 
In the recent past, significant advancement has been achieved in the use of genomics, transcriptomics and proteomics with aim of gaining insight on the genetic mechanism behind cotton resistance to V. dahliae, and a variety of $V$. dahliae resistance related genes have been revealed ${ }^{3,9-13}$. However, given the common evolving interaction between cotton and $V$. dahliae, it is critical to investigate the molecular pathways that determine $V$. dahliae pathogenicity. Due to the completion of genome sequencing and the advancement of bioinformatics methods, genomic and transcriptomic sequence knowledge of $V$. dahliae offers us with an ability to better understand its pathogenicity. The transcriptomic analysis of $V$. dahliae during microsclerotia establishment and initial infection phase have provided a glimpse of the genes essential for $V$. dahliae growth, microsclerotia formation, and infection ${ }^{14-16}$. For example, VdPKAC1, VMK1, VdMsb, VdGARP1, VDH1, Vayg1 and VGB were discovered to be intricate in the development of microsclerotia and the pathogenic phase of V. dahliae ${ }^{17,18}$; VdNEP, VdpevD1, VdNLP1 and VdNLP2 encode for effector proteins are linked in pathogenic responses ${ }^{19-22}$; VdFTF1, Vta2 and VdSge1 encode for transcriptional factors that regulate pathogenic genes ${ }^{23-25}$. Nonetheless, owing to the intricacy of $V$. dahliae pathogenic associated molecular mechanisms, the functions of these genes in the interaction between $V$. dahliae and cotton are yet to be fully understood. In the present study, we utilized V. dahliae fungus in infecting two Gossypium hirsutum L. cultivars, Xinluzao-36 (susceptible) and Zhongzhimian-2 (disease resistant) for $0 \mathrm{~h}, 24 \mathrm{~h}, 72 \mathrm{~h}$ and $120 \mathrm{~h}$ time intervals, so as to determine the molecular basis of $V$. dahliae host response mechanisms.

\section{Methodology}

V. dahliae culture. A defoliating V. dahliae Vd592 strain isolate which was acquired from Shihezi University, was cultured on potato dextrose agar (PDA) for a period of 7 days at a temperature of $25^{\circ} \mathrm{C}$. The cultured isolates were incubated in Czapek liquid medium for a period of 5 days at a temperature of $25^{\circ} \mathrm{C}$, so as to get the conidia. Using distilled water, the obtained spores were diluted to almost $1 \times 10^{6}$ spores per milliliter prior to inoculation.

Plant material and inoculation procedure. Xinluzao-36 (susceptible) and Zhongzhimian-2 (disease resistant) cotton cultivars that were used in this study were collected from Shihezi University, a kind gift from Professor Li Guoying. A syringe needle was used for acupuncture, and thereafter $10 \mathrm{~mL}$ of spore suspension was injected into the surrounding soil at the acupuncture site. Sampling was conducted at $0 \mathrm{~h}, 24 \mathrm{~h}, 72 \mathrm{~h}$ and $120 \mathrm{~h}$ time intervals, and afterwards subjected to transcriptome sequencing.

RNA extraction and sequencing. As per the manufacturer's guidelines, total RNA was extracted from the study samples using Trizol Reagent (Invitrogen, Life Technologies, Carlsbad, CA, USA). Using Oligo (dT) magnetic beads, purified poly (A) + mRNA was isolated from total RNA. By applying a fragmentation buffer to the mRNA, it was sheared into short fragments. Utilizing random primers and SuperScript II, first-strand cDNA was produced from the short poly $(\mathrm{A})+$ mRNA fragments. To yield a second-strand cDNA, RNaseH, DNA polymerase I, Buffer and dNTPs were added. End pairing of the double-stranded cDNA was achieved through addition of T4 DNA polymerase, Klenow Enzyme, and T4 polynucleotide kinase enzyme. Subsequently, DNA ligase was used to ligate the sequencing adapters to the fragments, and thereafter a single ' $\mathrm{A}$ ' base attachment with Klenow 3-5' exo-polymerase. The cDNA fragments were isolated on an agarose gel and used as sequencing templates for high-throughput sequencing. Sequencing was done on Illumina HiSeq 2000 platform.

Data and differentially expressed gene analysis. Quality assurance checks were performed on the sequenced raw reads. Poor quality reads were filtered out and adapter sequences together with reads containing ambiguous bases ' $\mathrm{N}$ ' and ones that had more than $20 \% \mathrm{Q}<30$ bases were discarded. Following Meyer et al., all sequences of less than $60 \mathrm{bp}$ were also discarded ${ }^{26}$. Using TopHat version $2.01^{27}$, the obtained clean reads were mapped to the G. hirsutum (AD1) reference genome ${ }^{28}$. The Cufflinks software (version 2.2.1) was utilized in measuring the abundance transcripts and differential gene expression ${ }^{27}$. Comparing gene expression levels amongst the two libraries was achieved through the relative transcript level of individually expressed gene was achieved through the calculation and normalization to the reads per kilobase of the exon model per million mapped reads (RPKM) ${ }^{29}$. Detection of the considerable variations and differences in gene expression patterns was done through the Chi-squared test that was incorporated in the IDEG6 software ${ }^{30}$. P-value threshold was defined through false discovery rate (FDR) so as to account for the multiple significance tests. In the present study, an FDR threshold $\leq 0.01$ and Fold change $\geq 2$ were accepted in determining the significantly expressed gene value differences.

In performing functional annotation of the obtained DEGs, Basic Local Alignment Search Tool (BLAST) alignment was executed via search in the Clusters of Orthologous Groups $(\mathrm{COG})^{31}$, SwissProt, Kyoto Encyclopedia of Genes and Genomes (KEGG) ${ }^{32,33}$ and Non-redundant $(\mathrm{Nr})$ protein databases with the E-value set at $\leq 1 \mathrm{e}-5$. Significant matches were carefully chosen in annotation of the DEGs. Blast2go software version 5.2.5 was utilized in annotating the DEGs' major Gene Ontology (GO) groups, including molecular functions, biological processes, and cellular components and the E-value $\leq 1 \mathrm{e}-5^{34}$.

Real-time quantitative PCR (RT-qPCR) analysis of the DEGs. Sequencing libraries were prepared from the total RNA, as described above. For RT-qPCR analysis, 6 randomly selected DEGs and cotton gene as the control were chosen, and primer design was done using DNAMAN 6.0 software package. RT-qPCR was done in an ABI 7900HT Real Time PCR System (Applied Biosystems, Life Technologies, Carlsbad, CA, USA) and a SYBR Premix Ex Taq (Tli RNaseH Plus), ROX plus (Takara Bio Inc., Shiga, Japan). The utilized thermocycling settings were: denaturation for $30 \mathrm{~s}$ at a temperature of $95^{\circ} \mathrm{C}$, followed by 40 cycles at a temperature of $95^{\circ} \mathrm{C}$ 


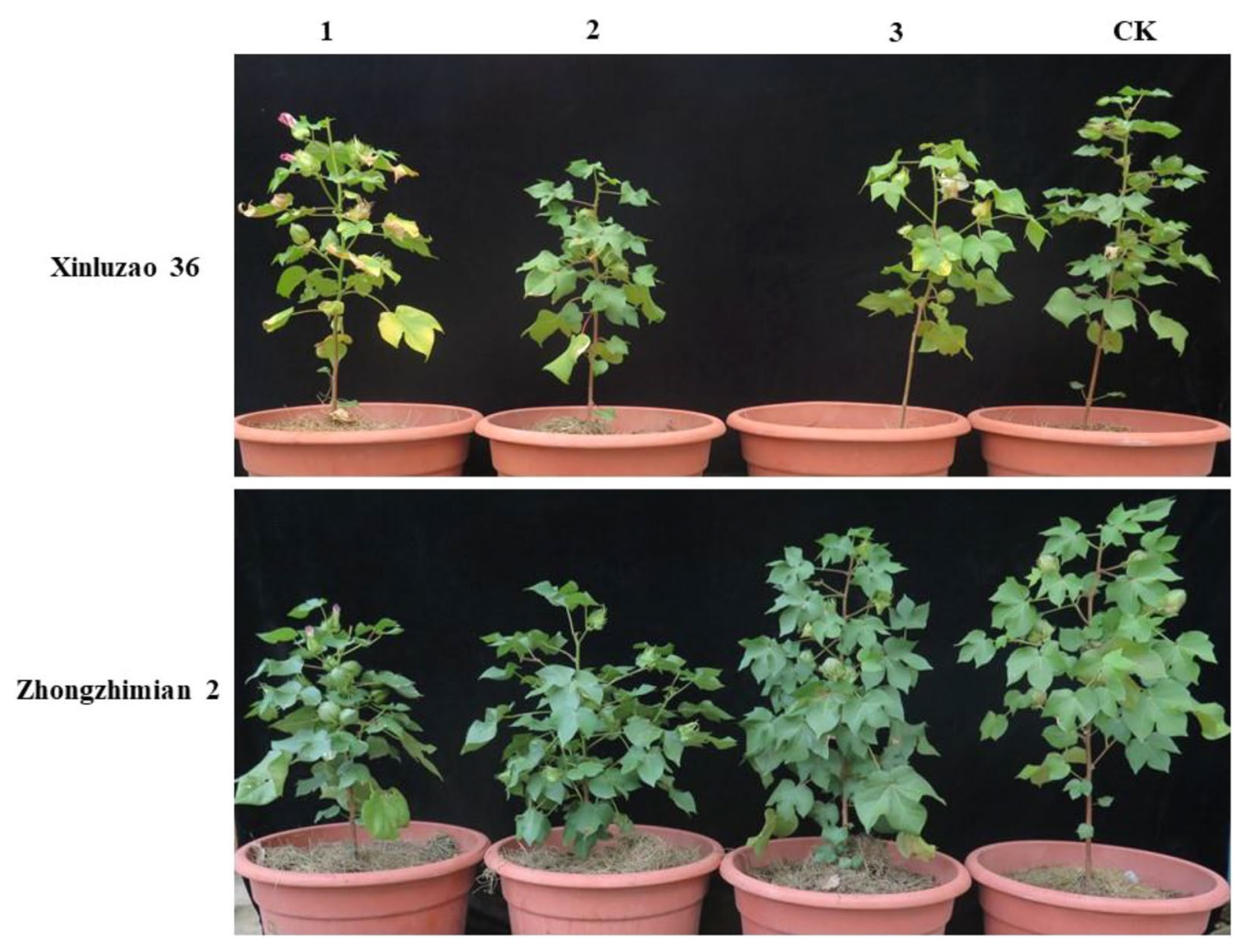

Figure 1. Morphologic and physiologic features of Xinluzao-36 and Zhongzhimian-2 subsequent to V. dahliae fungus infection.

for $5 \mathrm{~s}$, and $60^{\circ} \mathrm{C}$ for $30 \mathrm{~s}$. The $2-\Delta \Delta \mathrm{CT}$ procedure was used to normalize and calibrate the relative expression levels ${ }^{35}$. For each of the chosen genes, tests were performed in triplicates for all the biological and technical groups.

Statistical analysis and graphic presentation. R statistical package version 3.6.2 was utilized in experimental data analysis ${ }^{36}$. Prcomp software package was employed in Principal components analysis (PCA) analysis as well as graphic demonstration was executed via the scatterplot3d package. The boxplot package was used in the graphic demonstration of expression level distribution. The hierarchical clustering package was utilized in clustal analysis whereas the cluster tree graphic presentation and heatmap were achieved by means of the ggplots package. The WGCNA package version 1.70-3 was applied in preparing the graphical outlook of the network/ module construction ${ }^{37}$.

Statement. The two cotton cultivars that were used in this study were collected from Shihezi University. Its growth, harvest and use in this manuscript complies with relevant institutional, national, and international guidelines and legislation.

\section{Results}

The two cotton genotypes morphologically are identical, However, Xinluzhao-36 cultivar exhibited significant variations when exposed to $V$. dahliae fungus infection. This was exhibited by the leaves yellowing and starting to dry up from the edges. Further, it was observed that the Zhongzhimian-2 variety had a large biomass and yellowing of leaves compared to the Xinluzhao-36 cultivar (Fig. 1).

Sequencing and transcript identification. In this study, two cotton cultivars; Xinluzao-36 (susceptible) and Zhongzhimian-2 (disease resistant) exposed to $V$. dahliae fungus infection were utilized in RNA-Sequencing (Table 1). These two V. dahliae strains differ in their pathogenicity, in that the LT strain is a weak pathogenic defoliating isolate, whereas the Vd592 strain is a strong pathogenic defoliating isolate.

The root tissues of the two accessions were considered at three different treatment periods; the samples being labeled as S2-24 h, S2-72 h and S2-120 h and S3-24 h, S3-72 h, S3-120 h for the Xinluzao-36 cotton variant whereas T2-24 h, T2-72 h, T2-120 h and T3-24 h, T3-72 h, T3-120 h for the Zhongzhimian 2 cotton variant (Supp File 1). All the samples were sequenced in triplicates. The two upland cotton accessions were categorized as either $V$. dahliae susceptible variety (S2 and S3) or $V$. dahliae resistant variety (T2 and $\mathrm{T} 3$ ). CK group represented the control plants that grew in normal optimum conditions. To examine the transcriptomic contrasts during 


\begin{tabular}{|l|l|l|l|}
\hline \multirow{2}{*}{ Strains } & \multirow{2}{*}{ Source } & Disease index \\
\cline { 3 - 4 } & Xinluzao 36 (susceptible variety) & Zhongzhimian 2 (resistant variety) \\
\hline LT & Luntai, Xinjiang & 21.52 & 8.91 \\
\hline Vd592 & Xinjiang & 85.43 & 18.72 \\
\hline
\end{tabular}

Table 1. Strains and disease index table.

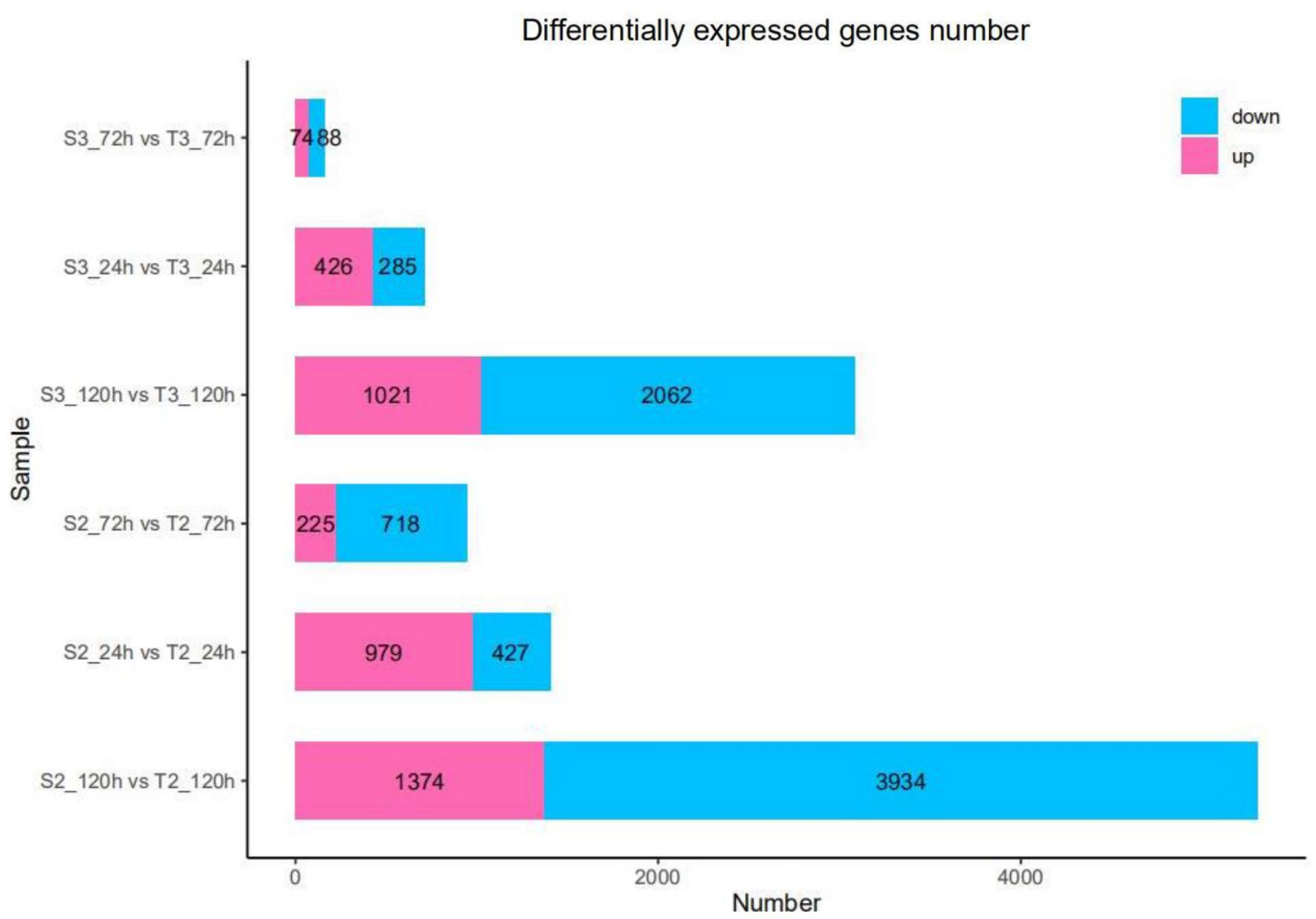

Figure 2. DEGs statistics at different stages of Xinluzao-36 and Zhongzhimian-2 after $V$. dahliae fungus infection. The up-regulated DEGs are shown in red, while the down-regulated DEGs are shown in blue in the stacked bar graphs.

$V$. dahliae fungus infection in the treated groups, total RNA was extracted from the root of the two varieties in three different treatment periods.

A total of 1106 million raw reads were obtained from 32 cDNA libraries, and 1097 million (99.38\%) clean reads were collected following data quality trimming processes (Supp File 1). For each library the proportion of the mapped data was between $82.97 \%$ and $90.01 \%$. In addition, the clean reads were mapped to G. hirsutum (AD1) reference genome in which 84.36 to 89.83 percent of the 32 samples obtained, producing 77.4 to $82.3 \%$ reads that uniquely mapped to the reference genome.

Identification and verification of differentially expressed genes (DEGs). Differential expression analysis showed that 162 genes were differentially expressed between the $\mathrm{S} 3-72 \mathrm{H}$ vs $\mathrm{T} 3-72 \mathrm{H}$ groups (74 upregulated and 88 downregulated), 711 genes were differentially expressed between S3-24H vs T3-24H group (426 upregulated and 285 downregulated), 3083 genes were differentially expressed between S3-120H vs T3-120H group (1021 upregulated and 2062 downregulated), 943 genes were differentially expressed between S2-72H vs T2-72H group (225 upregulated and 718 downregulated), 1406 genes were differentially expressed between S2-24H vs T2-24H group (979 upregulated and 427 downregulated) and 5308 genes were differentially expressed between S2-120H vs T2-120H group (1374 upregulated and 3034 downregulated) (Fig. 2). Notably, maximum number of differentially expressed genes was observed at $120 \mathrm{~h}$ post $V$. dahliae fungus infection.

In the Xinluzao-36 and Zhongzhimian-2 response to $V$. dahliae fungus infection, 13,541 genes were upregulated in at least one time-point when the treatment group was compared to the control group (Fig. $3 \mathrm{~A}$ ). In the S2_120h vs SCK, 5808 genes were differentially expressed while 4,936 were differentially expressed in the T2_120h vs TCK group. Equally, 4873 were differentially expressed in S3_120h vs SCK, and 6711 were differentially expressed in the T3_120h vs TCK group. Comparison between the treatment groups, 5308 were 
A

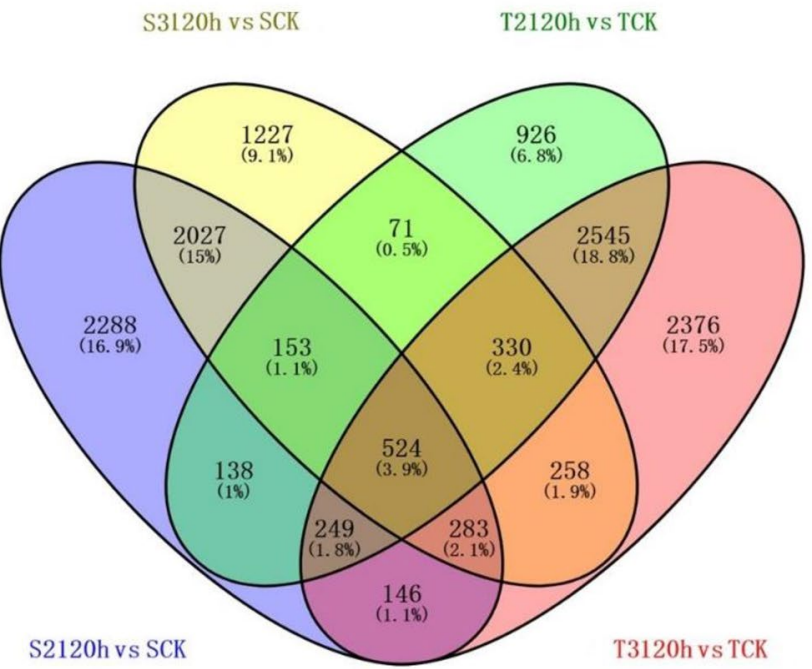

B

B S2120h vs T3120h

S3120h vs T2120h

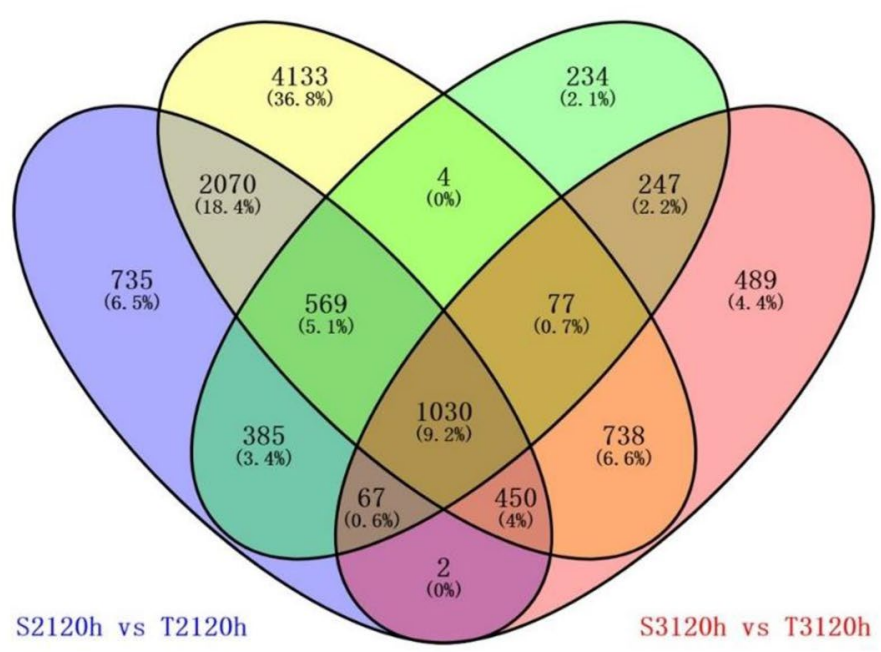

Figure 3. Venn diagram showing overlap of genes of G. hirsutum in response to V. dahliae. (A) Venn diagram showing overlap of up-regulated genes between the treatment groups and their respective control groups. (B) Overlap genes between the two treatment groups of in response to V. dahliae.

differentially expressed in the S2_120h vs T2_120h group while 3100 were differentially expressed in the S3_120h vs T3_120h group. Equally, 9071 were differentially expressed in S2_120h vs T3_120h, and 2613 were differentially expressed in the S3_120h vs T2_120h group (Fig. 3B).

Functional classification and enrichment analysis of DEGs. In comparisons of libraries made for the various time points, GO enrichment approaches were used to identify the putative roles of DEGs (Fig. 4). GO enriched categories of the DEGs in biological process groups were primarily linked in glucan metabolism process, cellular carbohydrate biosynthesis process, plant-type cell wall Biogenesis and polysaccharide biosynthesis. The GO enriched categories of the DEGs in cellular component were mostly linked to the anchored component of membrane, anchored component of plasma membrane, microtubule, microtubule associated complex and kinesin complex. GO enriched categories of the DEGs in molecular function were mostly linked to glucosyltransferase activity, copper iron binding, cellulose synthase activity and ATP-dependent microtubule motor activity (Fig. 4).

We also conducted enrichment analysis by mapping sequences to KEGG database groups in order to examine the roles of the differentially expressed transcripts. KEGG annotated DEG's were allocated to various classes, mainly related to biosynthesis of other secondary metabolites, signal transduction and carbohydrate metabolism. KEGG enrichment analyses as well showed DEGs were considerably enriched in pathways such as in ubiquitin biosynthesis, pyruvate metabolism, gluconeogenesis, glutathione metabolism, fructose and mannose metabolism, Flavonoid biosynthesis, fatty acid metabolism, cysteine and methionine metabolism (Fig. 5). 


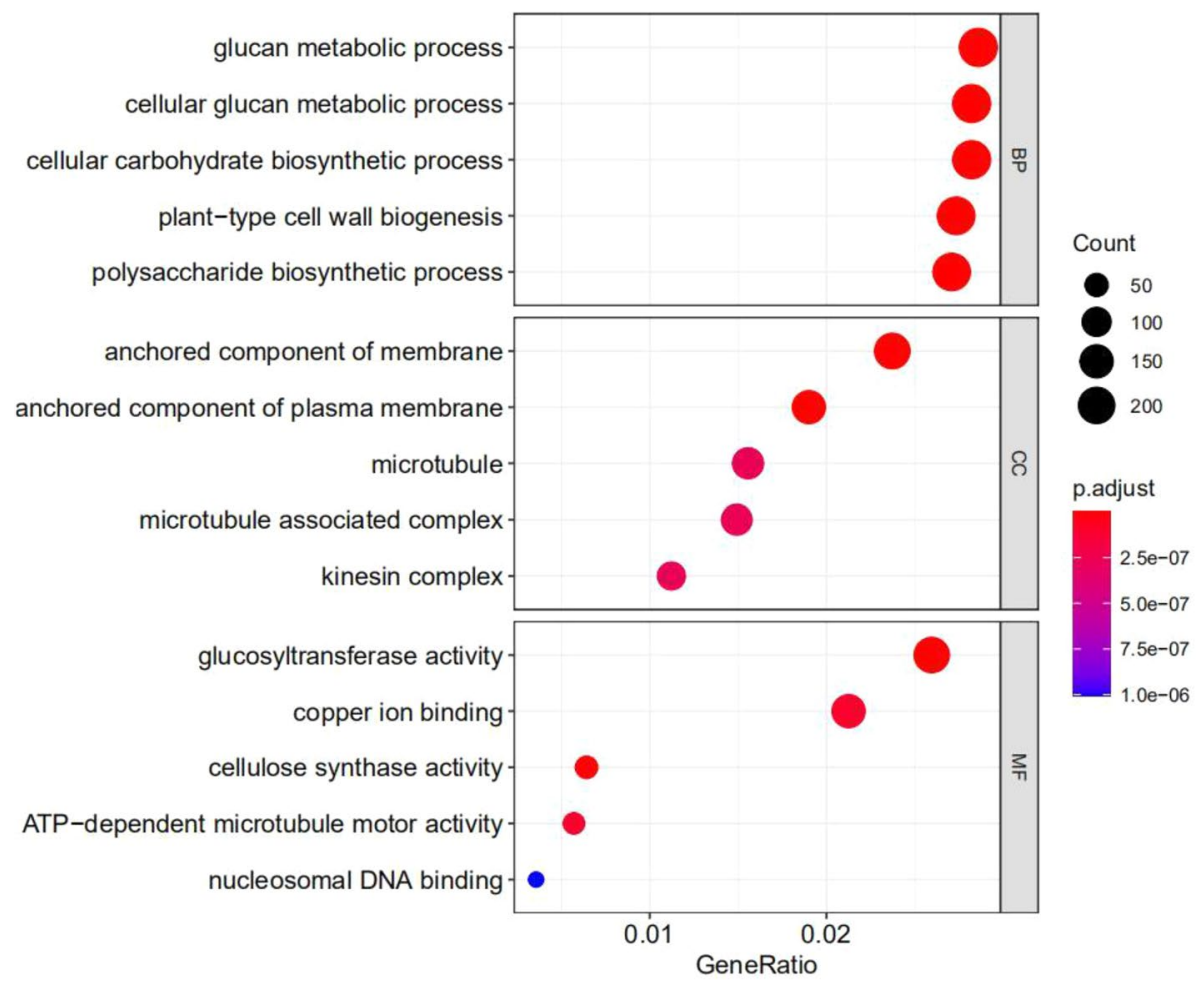

Figure 4. Gene Ontology (GO) term enrichment analysis. An FDR of $<0.05$ was used to pick significantly enriched GO terms.

Weighted gene expression clustering analysis. A popular approach to comparative genomics is to identify and annotate DEG sets for the purpose of mining the key genes. Therefore, WGCNA was conducted to further examine the basic molecular pathways and key genes affecting $V$. dahliae growth within the two cotton varieties. According to similar expression and similar functions, we finally selected all the differential genes $(13,541)$ for $120 \mathrm{~h}$ for the WGCNA analysis. The soft power was set at 15 since this was the lowest power required to attain nearly scale-free topology $(\mathrm{R} 2=0.865)$, and the number of co-expression modules was 16 modules in total (Fig. 6).

As per the correlation results between the modules and the two sample treatments in each phase, the pink module and S sample that are significantly positively correlated with T sample at $120 \mathrm{~h}$ and negatively correlated with S sample at $120 \mathrm{~h}$ were selected. The $120 \mathrm{~h}$ significant positive correlation of the $\mathrm{T}$ sample and the large negative correlation of the T sample $120 \mathrm{~h}$ brown module are used to construct the interactive network and hub screening of genes.

From the module trait correlation analysis, 3 modules had an analogous down-regulation in four time points that include T24 h, T72 h, and T120 h, in the MECyan, MEpurple, MEyellow and MEpink modules. Whereas MEbrown and MEred were upregulated at S120 hours post inoculation (hpi), and Mgrey encompassed upregulated genes that were at both S0 hpi and S24 hpi. Equally, MEyellow contained genes that were both upregulated in the T0hpi up to the T120hpi. Thus, each of these modules recognizes a gene set of G. hirsutum in response to $V$. dahliae fungus infection at specific time points (Fig. 7).

Networks displaying relationships among genes within co-expressed modules. With the goal of identifying main hub genes, we built a network of the identified co-expressed modules. In this study, we identified 11 hub genes that encode for different proteins associated with lignin and immune response, Auxin response factor, cell wall and vascular development, microtubule, Ascorbate transporter, Serine/threonine kinase and Immunity and drought (Fig. 8, Table 2).

qPCR validation. A set of differentially genes were randomly selected for detection and subsequent validation via qPCR, Fig. 9.

\section{Discussion}

Generally, Verticillium wilt restrains water and nutrient movement within the cotton vascular system, and considerably limits the crop yields. Equally, the photosynthetic rate and other related physiological traits in cotton genotypes are severely influenced by the Verticillium wilt ${ }^{38}$. Cotton genotypes display diverse reactions and resistance mechanisms to Verticillium wilt infection ${ }^{39}$. Mechanisms for $V$. dahliae Resistance may involve 


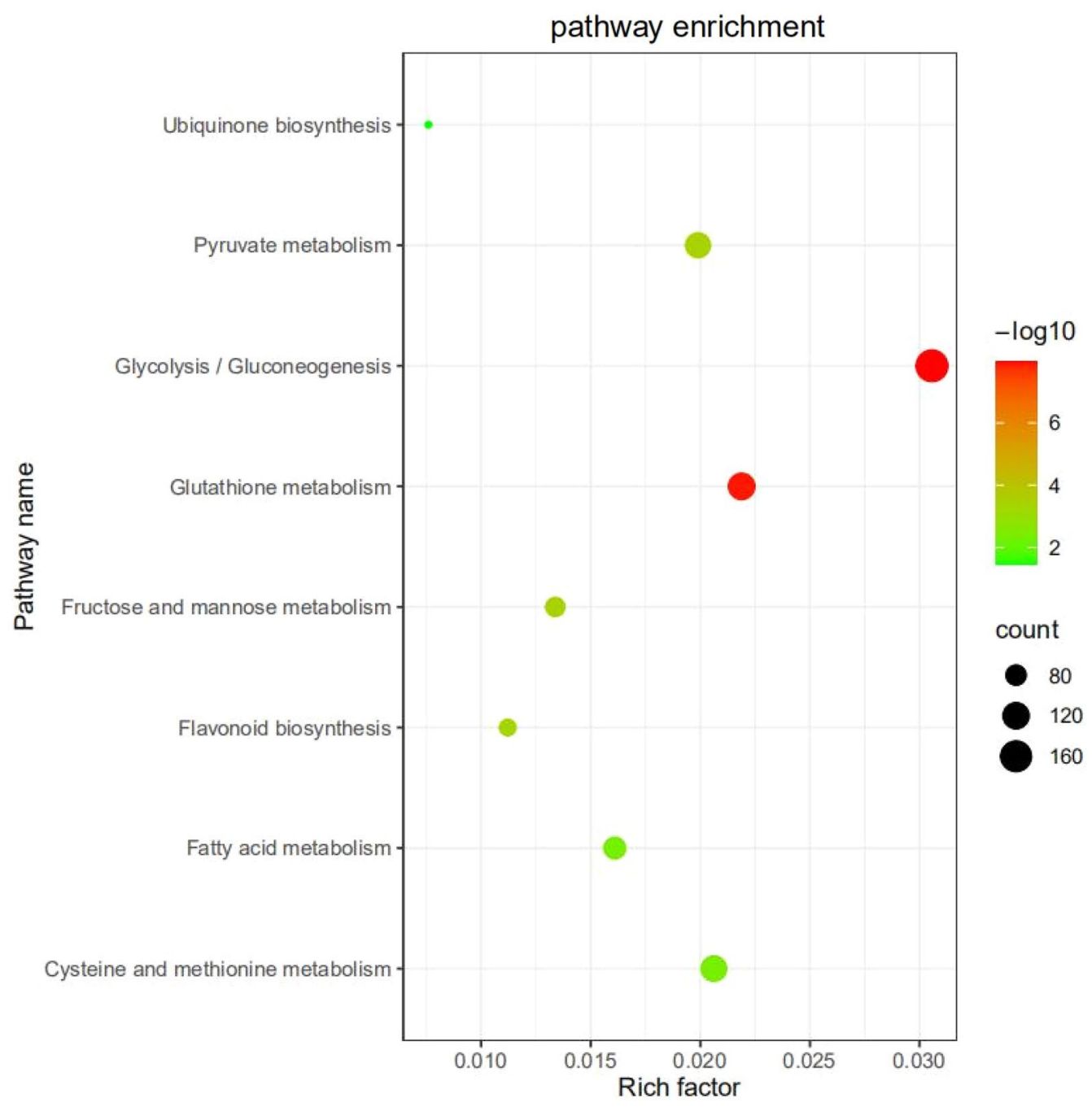

Figure 5. Analysis of KEGG pathways enrichment. Each circle in the diagram represents a KEGG metabolic pathway, and the size of the circle corresponds to the number of genes enriched in that pathway. The importance of DEG enrichment in a pathway is represented by the $-\log _{10}$ scale (qvalue).

modifications to the transcription factors, extracellular enzymes, cell wall, ethylene-associated signal transduction pathways, jasmonic acid pattern recognition receptors or salicylic acid ${ }^{40}$.

To aid infection and efficient colonization, pathogenic fungi in plants can develop a variety of cell walldegrading enzymes ${ }^{41,42}$, including pectinase, hemicellulase, cellulase, etc. Hydrolytic enzymes, especially cellulases and pectinases, have long been thought to play a key role in the expression of $V$. dahliae disease symptoms and pathogenesis ${ }^{43,44}$. The cell wall-degrading enzymes are virulence factors, for instance xyloglucan-specific endoglucanase ${ }^{45}$, fungal endopolygalacturonases ${ }^{46}$, as well operate as pathogen-associated molecular patterns (PAMPs). In particular, enzymes linked in cell wall degradation comprise non-catalytic domains, which are usually related to the fungal carbohydrate hydrolases, considered to be activators of the PAMP-triggered immunity (PTI) response in the oomycetes ${ }^{47,48}$. In V. dahliae, two Glycoside hydrolase 12 (GH12) proteins; VdEG1 and VdEG3 acted as PAMPs that triggered cell death and PTI independent of their enzyme action in Nicotiana benthamiana. Despite the fact that cell wall-degrading enzymes have also been linked to fungus pathogenicity, direct molecular evidence was insufficient. Herein, some of the enriched GO classifications are significantly related to the composition of the cell wall turn off. They include cellular carbohydrate biosynthesis process, plant-type cell wall Biogenesis and polysaccharide biosynthesis. Considering the main component of the cell wall is sugar, this observed pattern of enriched pathways may form part of the cell wall defense mechanism against pathogens at the initial stage of $V$. dahliae infection.

Phenylpropanoids, which naturally comprise of flavonoids and lignin, typically perform vital functions that are associated with biotic stress response in plant by both availing material units for physical barriers as well as synthesizing various antibiotic compound $s^{49,50}$. Further, lignin has been identified as a contributing factor in the resistance mechanisms of cotton to diseases ${ }^{51}$. Specifically, phenylpropane synthesis is associated with defense mechanisms in cotton ${ }^{52}$, whereas flavonoids are linked to cushion considerable stress-induced changes in the 


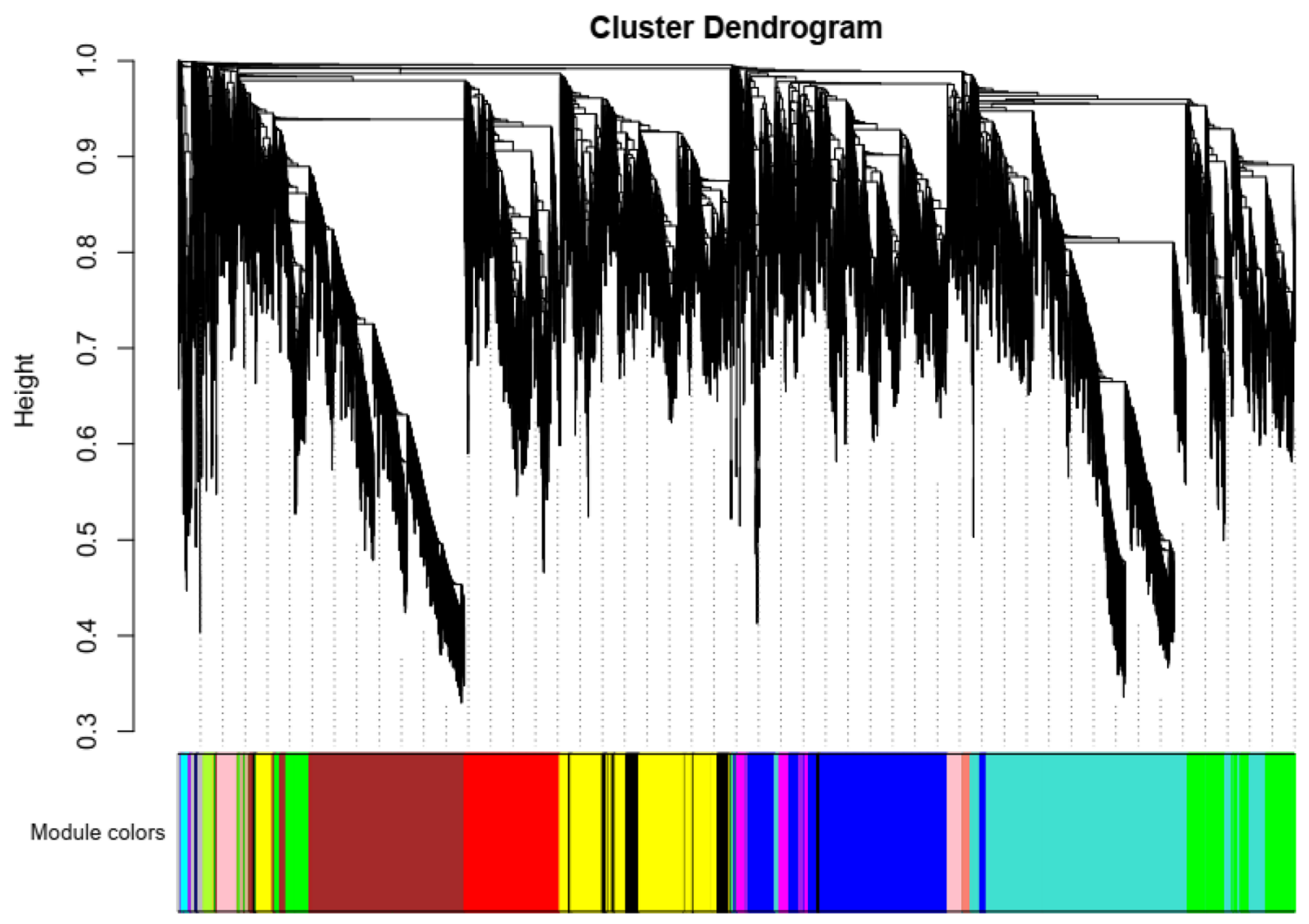

Figure 6. Weighted gene correlation network analysis (WGCNA). Hierarchical clustering of the topological overlap matrix for $V$. dahliae expression data.

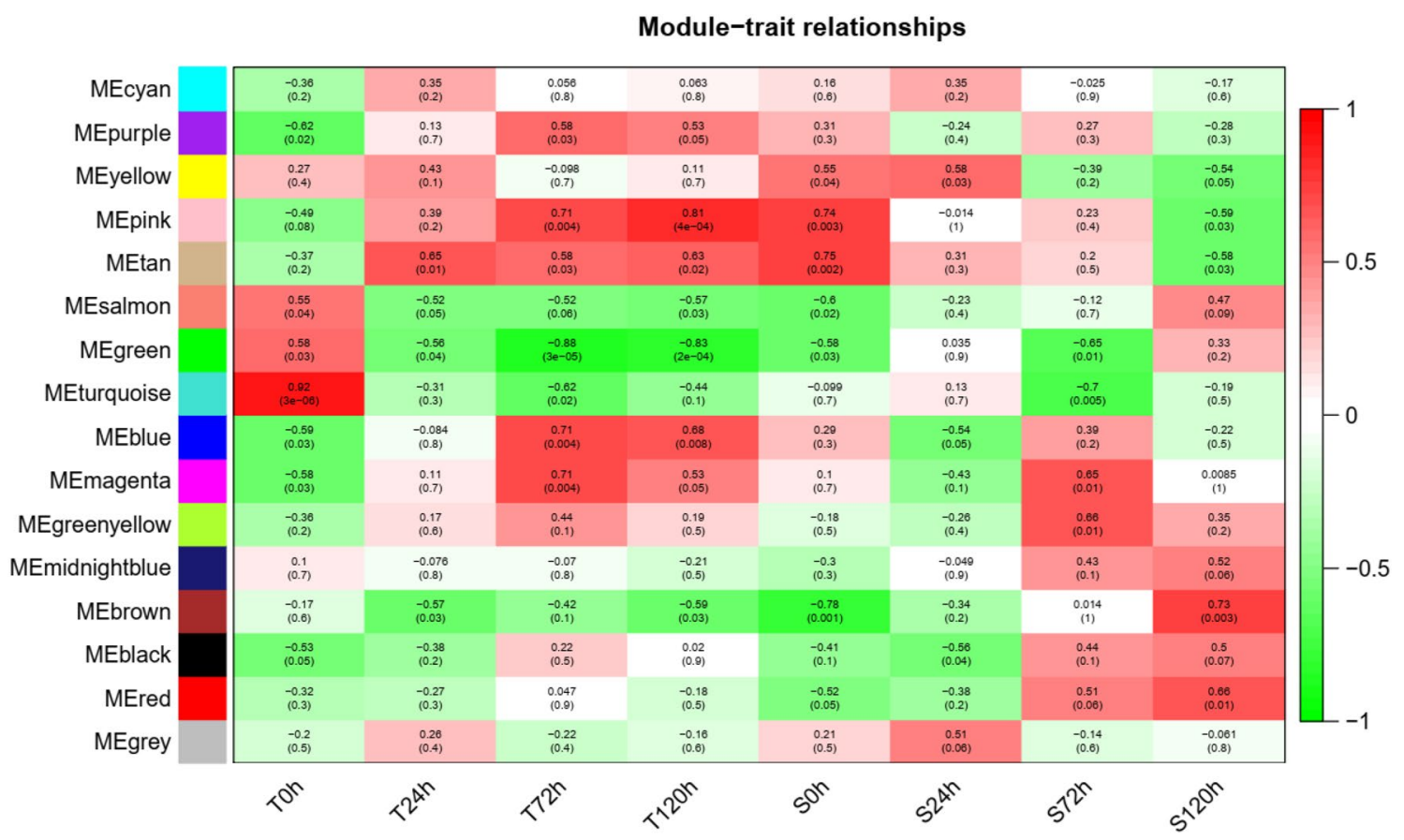

Figure 7. Module-trait correlation of G. hirsutum in response to V. dahliae fungus infection at specific time points. 


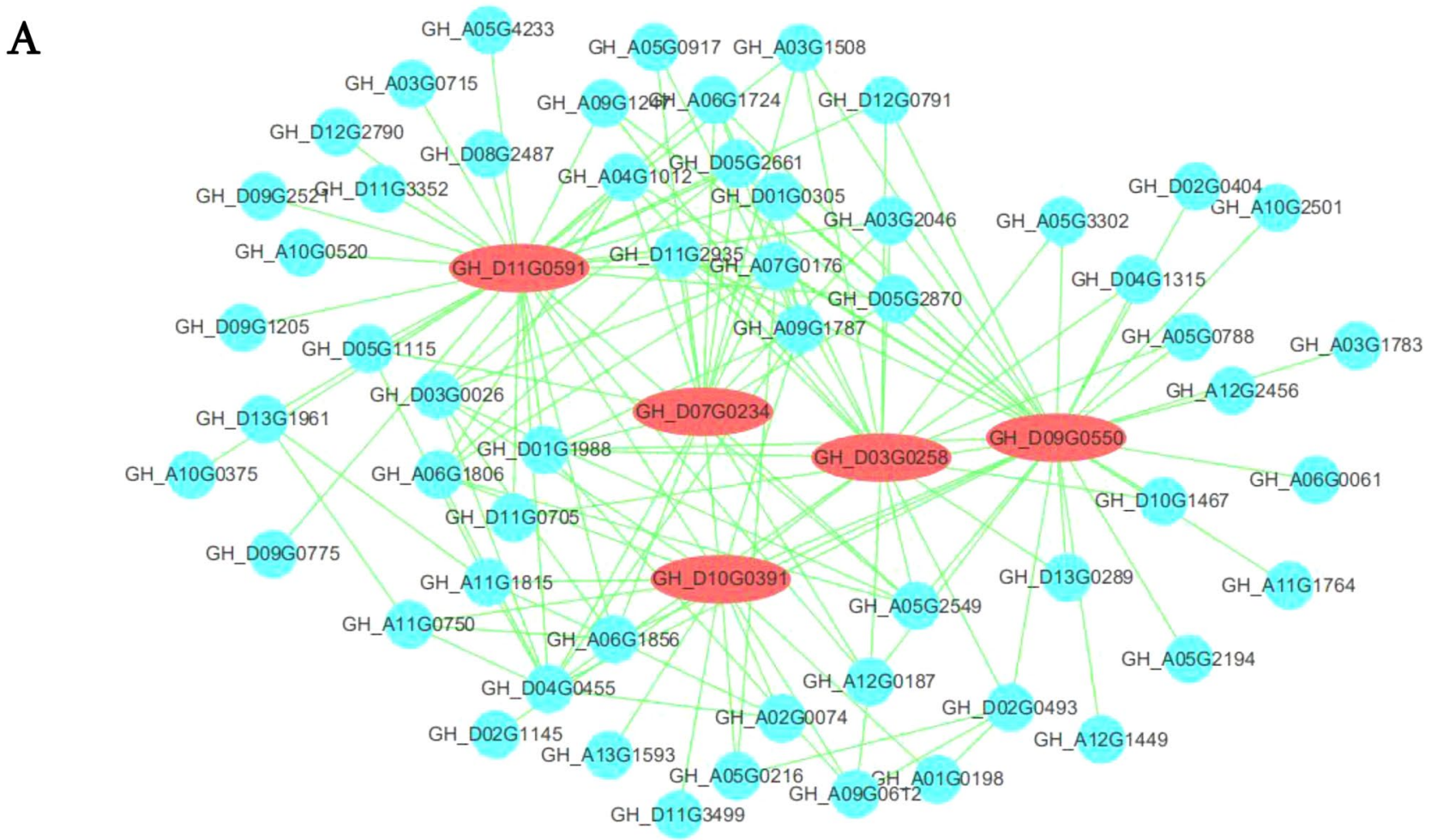

B

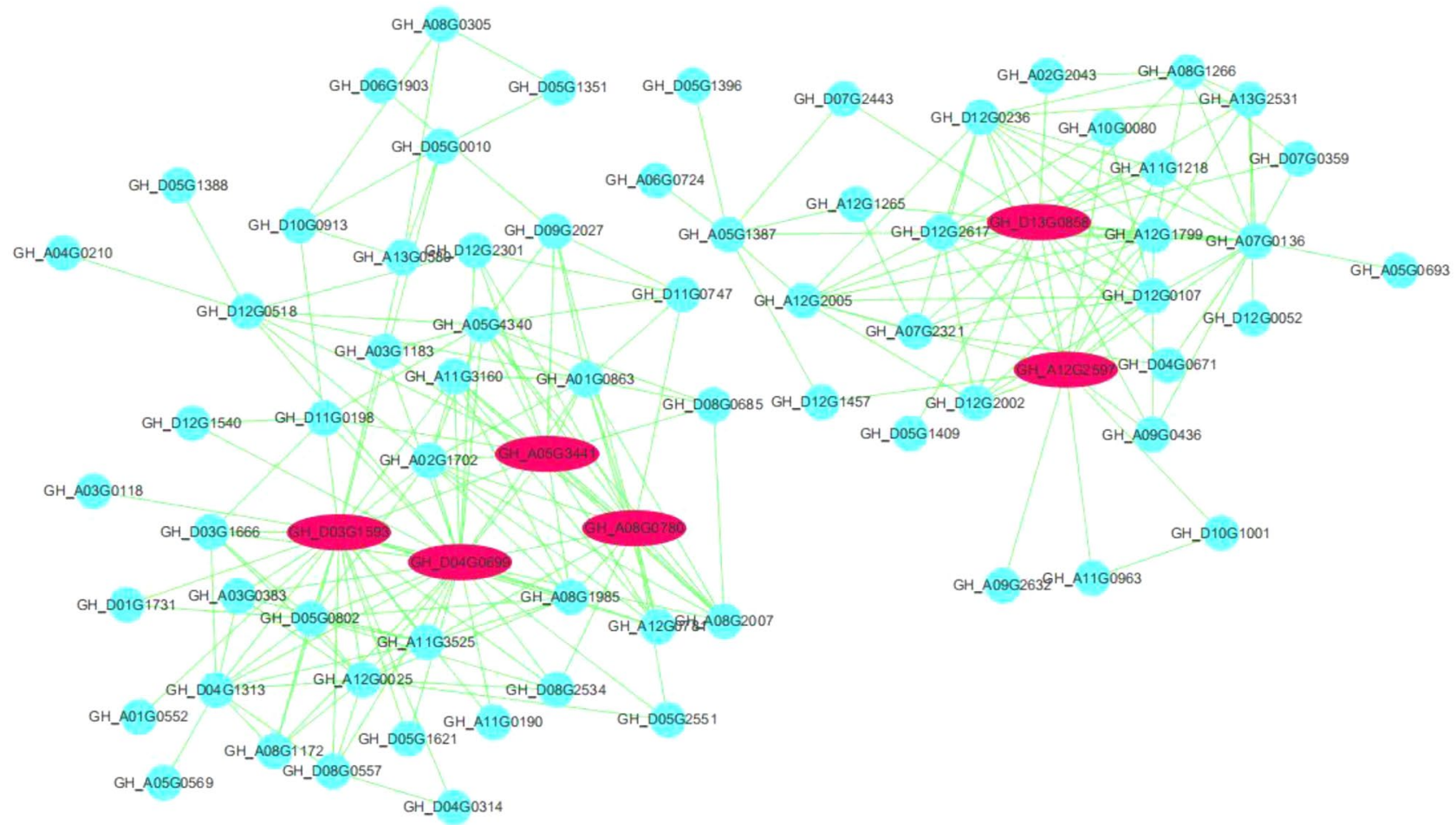

Figure 8. Co-expression network analysis of brown (A) and pink (B).

reactive oxygen species (ROS) homeostasis and modulation of the ROS-signaling pathway ${ }^{53}$. ROS are vital in defense signaling mechanism $s^{54}$ as well as controlling the programmed cell death by means of formation of the $\mathrm{HR}^{55}$. In this study, flavonoid biosynthesis was highly upregulated in the V. dahliae infected cotton varieties. In line with previously conducted studies that have described the significance of lignin pathway in lignification and reinforcement of cell walls as a vital processes in plant responses to fungal infection ${ }^{51,56}$, we identified significant lignin pathway enrichment that was more established in the disease resistant variety more than in the disease 


\begin{tabular}{|l|l|l|l|l|}
\hline Modules & Gene_id & Arabidopsis orthologs & Comparison rate & Predicted functions \\
\hline \multirow{4}{*}{ Brown } & GH_D07G0234 & AT2G26180 & 61.33 & Microtubule related \\
\cline { 2 - 5 } & GH_D09G0550 & AT5G51600 & 65.22 & Microtubule related \\
\cline { 2 - 5 } & GH_D10G0391 & AT2G34190 & 83.85 & Ascorbate transporter \\
\cline { 2 - 5 } & GH_D11G0591 & AT5G10010 & 67.73 & Serine/threonine kinase \\
\cline { 2 - 5 } & GH_D03G0258 & AT5G67270 & 65.99 & $\begin{array}{l}\text { B1 plays a role in microtubules during mitosis and early } \\
\text { cytokinesis }\end{array}$ \\
\hline \multirow{5}{*}{ Pink } & GH_A05G3441 & AT3G55830 & 65.34 & Related to lignin and immune response \\
\cline { 2 - 5 } & GH_A08G0780 & AT5G62000 & 51.63 & Auxin response factor \\
\cline { 2 - 5 } & GH_A12G2597 & AT5G65310 & 55.56 & Related to cell wall and vascular development \\
\cline { 2 - 5 } & GH_D13G0858 & AT1G13740 & 70.45 & Immunity and drought related \\
\cline { 2 - 5 } & GH_D03G1593 & AT1G07110 & 77.6 & $\begin{array}{l}\text { Encoding the bifunctional enzyme fructose 6-phosphate } \\
\text { 2-kinase/fructose-2,6 bisphosphatase }\end{array}$ \\
\cline { 2 - 5 } & GH_D04G0699 & AT3G55830 & 65.64 & Related to Arabidopsis immunity \\
\hline
\end{tabular}

Table 2. The hub genes detected in the two WGCNA modules.

susceptible $V$. dahliae variety. Although there is no much documented literature on the glutathione metabolism pathways in the transcriptome studies conducted on cotton and treated with $V$. dahliae, much has been reported in tomatoes elsewhere. Indeed, Sulfur is an effective macronutrient in plants as it can help them fight disease by forming sulfur-containing defense compounds (SDCs) including glutathione-S-transferase, glutathione, phytochelatins, as well as other sulfur-containing proteins $s^{57}$, and increased sulfur availability aids in boosting plant disease resistance to pathogen ${ }^{58-61}$. In accordance to previously conducted studies, SDC aggregation is quickly increased in pathogen-resistant cultivars compared to the susceptible cultivars. Similarly, other numerous studies have shown the importance of sulfur in disease resistance in plants ${ }^{62-64}$. In tomatoes, expression levels of genes linked to sulfate uptake that has been observed as well as the integration and the SDCs formation were all up-regulated, thus indicating that sulfur-enhanced defense may be playing a significant part in improved resistance of tomatoes to V. dahliae, as depicted by Rausch and Wachter ${ }^{57,65}$. Further, the increased GSH content together with other up-regulated genes expression associated with sulfur metabolism, like those that encode for glutathione-S-transferase, cysteine synthase and peptide methionine sulfoxide reductase, possibly play a part in enhancing the resistance against $V$. dahliae in tomatoes ${ }^{65}$. Intriguingly, Glutathione metabolism was upregulated in the KEGG enrichment pathway. Thus, it may be implicated in the resistance mechanisms of V. dahliae infection in cotton varieties.

WGCNA split the core DEG's into two modules, each providing a distinct metabolism pathway in relation to $V$. dahliae infection. From the recognized hub genes, co-expression network of upregulated hub genes comprised of Ascorbate transporter, Serine/threonine kinase, Auxin response factor, and Immunity and drought related genes. In accordance with GO term analysis, these hub genes were involved in the transport and in the immune response mechanisms. Plants utilize a wide variety of chemicals to defend them from pathogens. These chemical compounds may build up in the affected tissue at high levels ${ }^{66}$. Proteins encompassed in long distance transportation are important for the transfer of these protective compounds to other tissues and for the survival of plants under a viral attack ${ }^{67}$. The differentially expressed transporters recognized herein may have a part in transportation of secondary metabolites as well as the translocation of defense associated compounds that stimulate other mechanisms intricate in defense responses of plants when under a viral attack. Serine/threonine protein kinase (STK) performs a significant part in plant stress-signaling transduction pathway through phosphorylation ${ }^{68}$. Serine/threonin protein kinase (STK) is a major defensive signal transduction protein. The primary function of STK in plant-microbe systems is to sense and relay environmental signals from a pathogen ${ }^{69}$. Equally, phytohormone auxin also plays the key role in controlling many different characteristics of plant development, including lateral root initiation, elongation of the shoot, embryogenesis, vascular growth, tropical development and architecture of flowers and tissues ${ }^{70,71}$. Auxin response factors (ARFs), which are essential apparatuses of the auxin signal pathways, control the expression of auxin-responsive genes by binding directly in their promoter regions to the auxin-responsive variable ${ }^{72}$.

\section{Data availability}

This study data can be accessed through the NCBI Sequence Read Archive under Bio project ID number PRJNA745369, with SRA numbers SRR15144248, SRR15144249, SRR15144250, SRR15144251, SRR15144252, SRR15144253, SRR15144254, SRR15144255, SRR15144256, SRR15144257, SRR15144258, SRR15144259, SRR15144260, SRR15144261, SRR15144262, SRR15144263, SRR15144264, SRR15144265, SRR15144266, SRR15144267, SRR15144268, SRR15144269, SRR15144270, SRR15144271, SRR15144272, SRR15144273, SRR15144274, SRR15144275, SRR15144276, SRR15144277, SRR15144278, SRR15144279, SRR15144280, SRR15144281, SRR15144282, SRR15144283, SRR15144284, SRR15144285, SRR15144286, SRR15144287, SRR15144288 and SRR15144289. 


\section{GH_D04G0699}

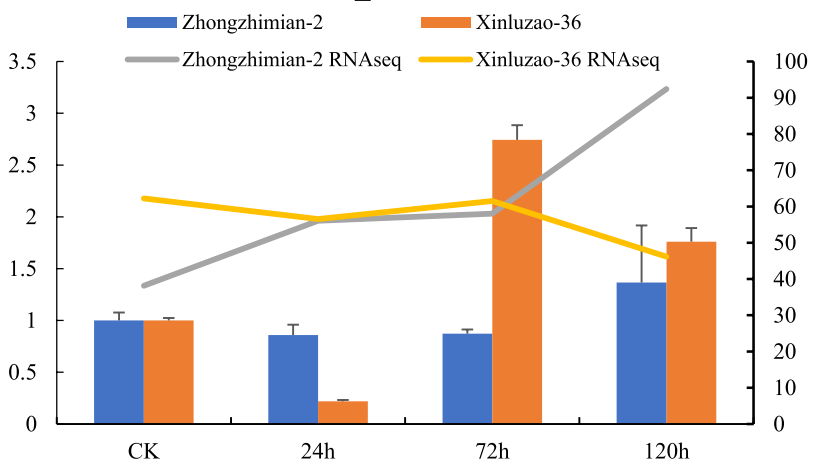

\section{GH A08G0780}

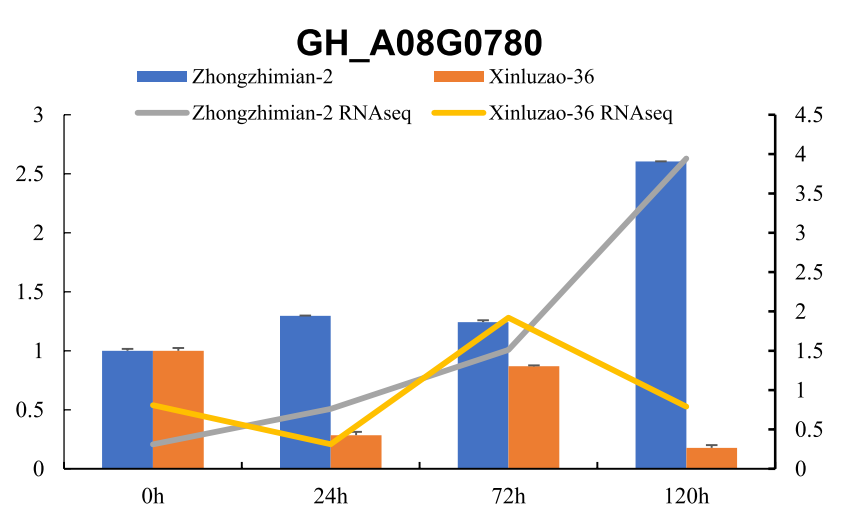

GH_D09G0550

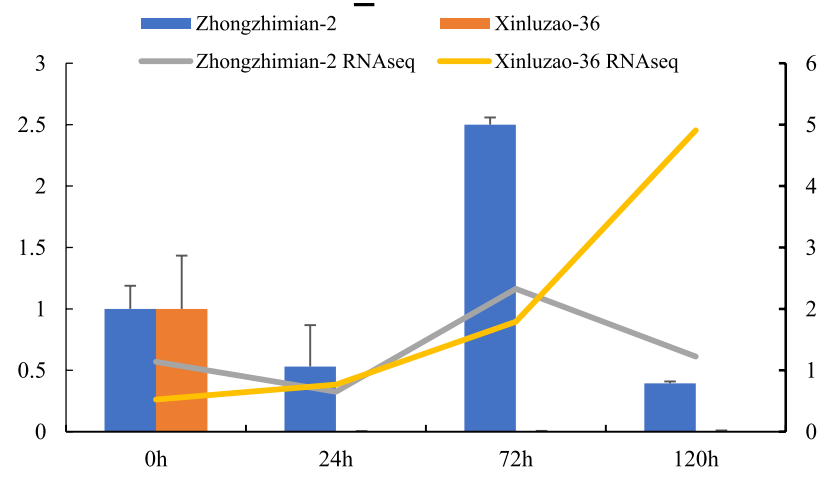

\section{GH_D07G0234}

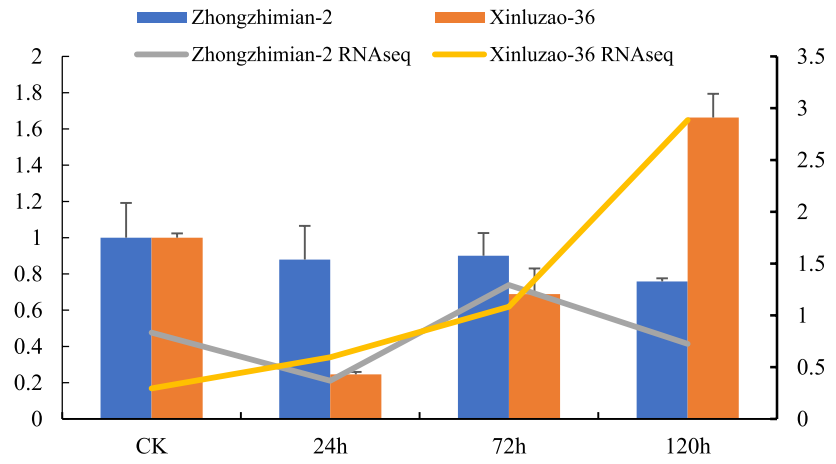

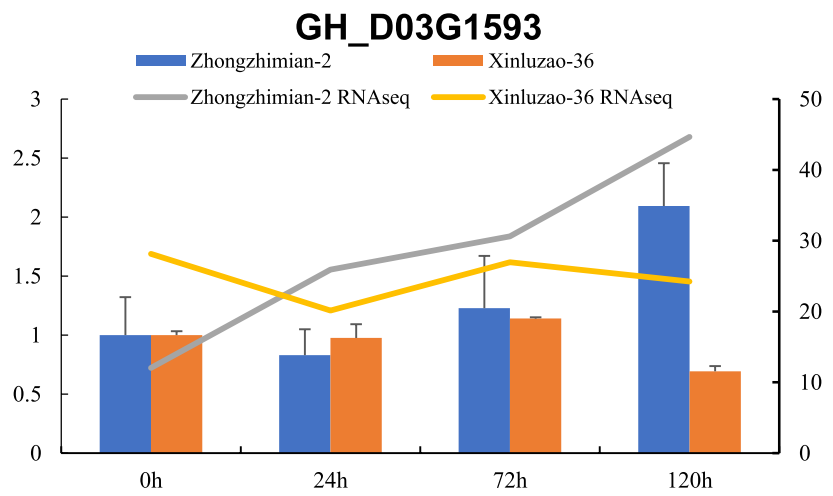

50

40

30

20

$0 \mathrm{~h}$

24

$72 \mathrm{~h}$

GH_A05G3441

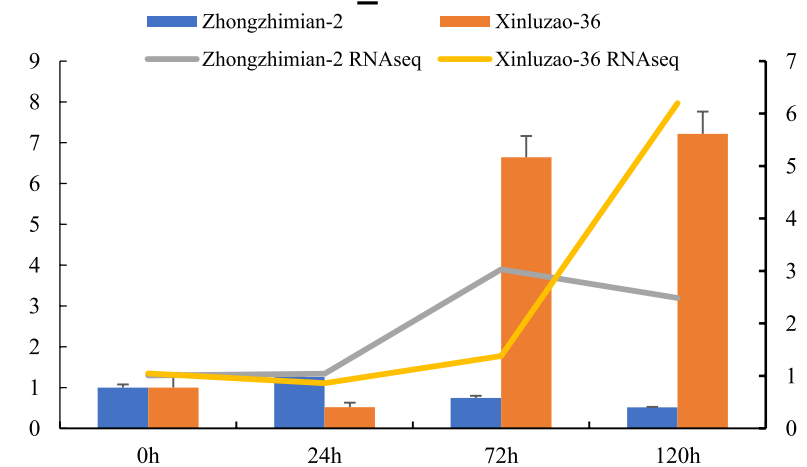

Figure 9. Real time-PCR validation of DE transcripts.

Received: 5 May 2021; Accepted: 6 September 2021

Published online: 18 October 2021

\section{References}

1. Tian, J. et al. Expression of baculovirus anti-apoptotic genes p35 and op-iap in cotton (Gossypium hirsutum L.) enhances tolerance to Verticillium wilt. PLoS ONE 5, e14218 (2010).

2. Sun, Q. et al. Analysis of sea-island cotton and upland cotton in response to Verticillium dahliae infection by RNA sequencing. BMC Genomics 14, 852 (2013).

3. Zhang, W. et al. Large-scale identification of Gossypium hirsutum genes associated with Verticillium dahliae by comparative transcriptomic and reverse genetics analysis. PLOS ONE 12, e0181609 (2017).

4. Tzima, A., Paplomatas, E. J., Rauyaree, P. \& Kang, S. Roles of the catalytic subunit of cAMP-dependent protein kinase A in virulence and development of the soilborne plant pathogen Verticillium dahliae. Fungal Genet. Biol. 47, 406-415 (2010).

5. Zhao, Y.-L., Zhou, T.-T. \& Guo, H.-S. Hyphopodium-specific VdNoxB/VdPls1-dependent ROS-Ca2+ signaling is required for plant infection by Verticillium dahliae. PLoS Pathog. 12, e1005793 (2016).

6. Sink, K. C. \& Grey, W. E. A root-injection method to assess Verticillium wilt resistance of peppermint (Mentha $x$ piperita L.) and its use in identifying resistant somaclones of cv. Black Mitcham. Euphytica 106, 223-230 (1999).

7. Daayf, F., Nicole, M., Boher, B., Pando, A. \& Geiger, J. P. Early vascular defense reactions of cotton roots infected with a defoliating mutant strain of Verticillium dahliae. Eur. J. Plant Pathol. 103, 125-136 (1997). 
8. Shaban, M. et al. Physiological and molecular mechanism of defense in cotton against Verticillium dahliae. Plant Physiol. Biochem. 125, 193-204 (2018).

9. Gao, W. et al. Proteomic and virus-induced gene silencing (VIGS) analyses reveal that gossypol, brassinosteroids, and jasmonic acid contribute to the resistance of cotton to Verticillium dahliae. Mol. Cell. Proteomics 12, 3690-3703 (2013).

10. Tan, X. P. et al. Expression pattern of (+)- $\delta$-cadinene synthase genes and biosynthesis of sesquiterpene aldehydes in plants of Gossypium arboreum L... Planta 210, 644-651 (2000).

11. Xu, Y. H., Wang, J. W., Wang, S., Wang, J. Y. \& Chen, X. Y. Characterization of GaWRKY1, a cotton transcription factor that regulates the sesquiterpene synthase gene $(+)-\delta$-cadinene synthase-A. Plant Physiol. 135, 507-515 (2004).

12. Jun, Z. et al. Overexpression of GbRLK, a putative receptor-like kinase gene, improved cotton tolerance to Verticillium wilt. Sci. Rep. https://doi.org/10.1038/srep15048 (2015).

13. Zhang, Z. et al. Constitutive expression of a novel antimicrobial protein, $\mathrm{Hcm} 1$, confers resistance to both Verticillium and Fusarium wilts in cotton. Sci. Rep. https://doi.org/10.1038/srep20773 (2016).

14. Luo, X., Xie, C., Dong, J. \& Yang, X. Comparative transcriptome analysis reveals regulatory networks and key genes of microsclerotia formation in the cotton vascular wilt pathogen. Fungal Genet. Biol. 126, 25-36 (2019).

15. Duressa, D. et al. RNA-seq analyses of gene expression in the microsclerotia of Verticillium dahliae. BMC Genomics 14, 607 (2013).

16. Hu, D. et al. Whole genome wide expression profiles on germination of Verticillium dahliae microsclerotia. PLoS ONE 9, e100046 (2014).

17. Tzima, A. K., Paplomatas, E. J., Rauyaree, P., Ospina-Giraldo, M. D. \& Kang, S. VdSNF1, the sucrose nonfermenting protein kinase gene of Verticillium dahliae, is required for virulence and expression of genes involved in cell-wall degradation. Mol. Plant-Microbe Interact. 24, 129-142 (2011).

18. Liu, S. Y. et al. Molecular characterization and functional analysis of a specific secreted protein from highly virulent defoliating Verticillium dahliae. Gene 529, 307-316 (2013).

19. Wang, J. Y. et al. VdNEP, an elicitor from Verticillium dahliae, induces cotton plant wilting. Appl. Environ. Microbiol. 70, 4989-4995 (2004).

20. Liu, W. et al. Mutational analysis of the Verticillium dahliae protein elicitor PevD1 identifies distinctive regions responsible for hypersensitive response and systemic acquired resistance in tobacco. Microbiol. Res. 169, 476-482 (2014).

21. Santhanam, P. et al. Evidence for functional diversification within a fungal Nep1-like protein family. Mol. Plant-Microbe Interact. 26, 278-286 (2013).

22. Zhou, B. J., Jia, P. S., Gao, F. \& Guo, H. S. Molecular characterization and functional analysis of a necrosis- and ethylene-inducing, protein-encoding gene family from Verticillium dahliae. Mol. Plant-Microbe Interact. 25, 964-975 (2012).

23. Tran, V. T. et al. Verticillium transcription activator of adhesion Vta2 suppresses microsclerotia formation and is required for systemic infection of plant roots. New Phytol. 202, 565-581 (2014).

24. Santhanam, P. \& Thomma, B. P. H. J. Verticillium dahliae sgel differentially regulates expression of candidate effector genes. Mol. Plant-Microbe Interact. 26, 249-256 (2013).

25. Zhang, W. Q. et al. Verticillium dahliae transcription factor VdFTF1 regulates the expression of multiple secreted virulence factors and is required for full virulence in cotton. Mol. Plant Pathol. 19, 841-857 (2018).

26. Meyer, E. et al. Sequencing and de novo analysis of a coral larval transcriptome using 454 GSFlx. BMC Genomics 10, 219 (2009).

27. Trapnell, C., Pachter, L. \& Salzberg, S. L. TopHat: Discovering splice junctions with RNA-Seq. Bioinformatics 25, 1105-1111 (2009).

28. Wang, M. et al. Reference genome sequences of two cultivated allotetraploid cottons, Gossypium hirsutum and Gossypium barbadense. Nat. Genet. 51, 224-229 (2018).

29. Mortazavi, A., Williams, B. A., McCue, K., Schaeffer, L. \& Wold, B. Mapping and quantifying mammalian transcriptomes by RNASeq. Nat. Methods 5, 621-628 (2008).

30. Romualdi, C., Bortoluzzi, S., D’Alessi, F. \& Danieli, G. A. IDEG6: A web tool for detection of differentially expressed genes in multiple tag sampling experiments. Physiol. Genomics 12, 159-162 (2003).

31. Tatusov, R. L., Galperin, M. Y., Natale, D. A. \& Koonin, E. V. The COG database: A tool for genome-scale analysis of protein functions and evolution. Nucleic Acids Res. 28, 33-36 (2000).

32. Minoru, K., Yoko, S., Masayuki, K., Miho, F. \& Mao, T. KEGG as a reference resource for gene and protein annotation. Nucleic Acids Res. 44, D457-D462 (2016).

33. Kanehisa, M. \& Sato, Y. KEGG Mapper for inferring cellular functions from protein sequences. Protein Sci. 29, $28-35$ (2020).

34. Conesa, A. \& Götz, S. Blast2GO: A comprehensive suite for functional analysis in plant genomics. Int. J. Plant Genomics 2008, $1-12(2008)$.

35. Livak, K. J. \& Schmittgen, T. D. Analysis of relative gene expression data using real-time quantitative PCR and the $2-\Delta \Delta C T$ method. Methods 25, 402-408 (2001).

36. R Core Team. R: A Language and Environment for Statistical Computing (2018).

37. Langfelder, P. \& Horvath, S. WGCNA: An R package for weighted correlation network analysis. BMC Bioinform. 9, 1-13 (2008).

38. Ayele, A. G., Wheeler, T. A. \& Dever, J. K. Impacts of Verticillium wilt on photosynthesis rate, lint production, and fiber quality of greenhouse-grown cotton (Gossypium hirsutum). Plants 9, 857 (2020).

39. Hampton, R. E., Wullschleger, S. D. \& Oosterhuis, D. M. Impact of Verticillium wilt on net photosynthesis, respiration and photorespiration in field-grown cotton (Gossypium hirsutum L.). Physiol. Mol. Plant Pathol. 37, 271-280 (1990).

40. Song, R., Li, J., Xie, C., Jian, W. \& Yang, X. An overview of the molecular genetics of plant resistance to the Verticillium wilt pathogen Verticillium dahliae. Int. J. Mol. Sci. 21, 1120 (2020).

41. Eboigbe, L., Tzima, A. K., Pap Lomatas, E. J. \& Typas, M. N. A. The role of the B-1,6-endoglucanase gene vegB in physiology and virulence of Verticillium dahliae. Phytopathol. Mediterr. 53, 94 (2014).

42. El-Bebany, A. F. et al. Induction of putative pathogenicity-related genes in Verticillium dahliae in response to elicitation with potato root extracts. Environ. Exp. Bot. 72, 251-257 (2011).

43. Pegg, G. F. 1981. Biochemistry and physiology of pathogenesis. In Fungal Wilt Diseases of Plants (ed. Pegg, G. F.) (Elsevier, 1981).

44. Isshiki, A., Akimitsu, K., Yamamoto, M. \& Yamamoto, H. Endopolygalacturonase is essential for citrus black rot caused by Alternaria citri but not brown spot caused by Alternaria alternata. Mol. Plant-Microbe Interact. 14, 749-757 (2001).

45. Ma, Z. et al. A phytophthora sojae glycoside hydrolase 12 protein is a major virulence factor during soybean infection and is recognized as a PAMP. Plant Cell 27, 2057-2072 (2015).

46. Zhang, L. et al. Fungal endopolygalacturonases are recognized as microbe-associated molecular patterns by the arabidopsis receptor-like protein responsiveness to botrytis polygalacturonases. Plant Physiol. 164, 352-364 (2014).

47. Gaulin, E. et al. Cellulose binding domains of a Phytophthora cell wall protein are novel pathogen-associated molecular patterns. Plant Cell 18, 1766-1777 (2006).

48. Larroque, M. et al. The unique architecture and function of cellulose-interacting proteins in oomycetes revealed by genomic and structural analyses. BMC Genomics 13, 605 (2012).

49. La Camera, S. et al. Metabolic reprogramming in plant innate immunity: The contributions of phenylpropanoid and oxylipin pathways. Immunol. Rev. 198, 267-284 (2004).

50. Vogt, T. Phenylpropanoid biosynthesis. Mol. Plant 3, 2-20 (2010).

51. Xu, L. et al. Lignin metabolism has a central role in the resistance of cotton to the wilt fungus Verticillium dahliae as revealed by RNA-Seq-dependent transcriptional analysis and histochemistry. J. Exp. Bot. 62, 5607-5621 (2011). 
52. Bu, B. et al. A fungal protein elicitor PevD1 induces Verticillium wilt resistance in cotton. Plant Cell Rep. 33, 461-470 (2014).

53. Brunetti, C., Fini, A., Sebastiani, F., Gori, A. \& Tattini, M. Modulation of phytohormone signaling: A primary function of flavonoids in plant-environment interactions. Front. Plant Sci. https://doi.org/10.3389/fpls.2018.01042 (2018).

54. Eckardt, N. A. The plant cell reviews plant immunity: Receptor-like kinases, ROS-RLK crosstalk, quantitative resistance, and the growth/defense trade-off. Plant Cell 29, 601-602 (2017).

55. Tamás, L. et al. Role of reactive oxygen species-generating enzymes and hydrogen peroxide during cadmium, mercury and osmotic stresses in barley root tip. Planta 231, 221-231 (2010).

56. Naoumkina, M. A. et al. Genome-wide analysis of phenylpropanoid defence pathways. Mol. Plant Pathol. 11, 829-846 (2010).

57. Rausch, T. \& Wachter, A. Sulfur metabolism: A versatile platform for launching defence operations. Trends Plant Sci. 10, 503-509 (2005).

58. Bollig, K., Specht, A., Myint, S. S., Zahn, M. \& Horst, W. J. Sulphur supply impairs spread of Verticillium dahliae in tomato. Eur. J. Plant Pathol. 135, 81-96 (2013).

59. Klikocka, $\mathrm{H}$. Influence of NPK fertilization enriched with S, Mg, and micronutrients contained in liquid fertilizer Insol 7 on potato tubers yield (Solanum tuberosum L.) and infestation of tubers with Streptomyces scabies and Rhizoctonia solani. J. Elementol. 14, 271 (2009).

60. Freitas, A. S. et al. Spatial distribution of Yellow sigatoka leaf spot correlated with soil fertility and plant nutrition. Precis. Agric. 17, 93-107 (2016).

61. Dubuis, P.-H., Marazzi, C., Stadler, E. \& Mauch, F. Sulphur deficiency causes a reduction in antimicrobial potential and leads to increased disease susceptibility of oilseed rape. J. Phytopathol. 153, 27-36 (2005).

62. Cooper, R. W. et al. Detection and cellular localization of elemental sulphur in disease-resistant genotypes of Theobroma cacao. Nature 379, 159-162 (1996).

63. Klug, K. et al. Spatial gene expression analysis in tomato hypocotyls suggests cysteine as key precursor of vascular sulfur accumulation implicated in Verticillium dahliae defense. Physiol. Plant. 153, 253-268 (2015).

64. Resende, M. L. V. et al. Novel phytoalexins including elemental sulphur in the resistance of cocoa (Theobroma cacao L.) to Verticillium wilt (Verticillium dahliae Kleb.). Physiol. Mol. Plant Pathol. 48, 347-359 (1996).

65. Fu, X., Li, C., Zhou, X., Liu, S. \& Wu, F. Physiological response and sulfur metabolism of the V. dahliae-infected tomato plants in tomato/potato onion companion cropping. Sci. Rep. https://doi.org/10.1038/srep36445 (2016).

66. Nour-Eldin, H. H. et al. NRT/PTR transporters are essential for translocation of glucosinolate defence compounds to seeds. Nature 488, 531-534 (2012).

67. Sade, D. et al. Involvement of the hexose transporter gene LeHT1 and of sugars in resistance of tomato to tomato yellow leaf curl virus. Mol. Plant 6, 1707-1710 (2013).

68. Zhang, Y. et al. Ectopic expression of a novel Ser/Thr protein kinase from cotton (Gossypium barbadense), enhances resistance to Verticillium dahliae infection and oxidative stress in Arabidopsis. Plant Cell Rep. 32, 1703-1713 (2013).

69. Zhou, J., Loh, Y. T., Bressan, R. A. \& Martin, G. B. The tomato gene Ptil encodes a serine/threonine kinase that is phosphorylated by Pto and is involved in the hypersensitive response. Cell 83, 925-935 (1995).

70. Domagalska, M. A. \& Leyser, O. Signal integration in the control of shoot branching. Nat. Rev. Mol. Cell Biol. 12, 211-221 (2011).

71. Teale, W. D., Paponov, I. A. \& Palme, K. Auxin in action: Signalling, transport and the control of plant growth and development. Nat. Rev. Mol. Cell Biol. 7, 847-859 (2006).

72. Guilfoyle, T. J. \& Hagen, G. Auxin response factors. Curr. Opin. Plant Biol. 10, 453-460 (2007).

\section{Acknowledgements}

This work was supported by funds from the National Key Research and Development Program of China (2016YFD0101419) and the Project of Innovation Team Building in Key Areas of Xinjiang Production and Construction Corps [XPCC] (2019CB008).

\section{Author contributions}

Conceptualization, G.Z., Q.C., and G.S.; Data curation, G.Z., Z.Z., P.M., and Y.Q.; Formal analysis, G.Z., Z.Z., and G.S.; Funding acquisition, Q.C., and G.S.; Methodology, G.Z., P.M., and G.S.; Project administration, G.Z., Q.C., and G.S.; Resources, G.S., Y.Q. and Q.C.; Supervision, Q.C.; Validation, G.Z., Z.Z. and Y.Q.; Writing - original draft, G.Z.; Writing - review \& editing G.Z., Z.Z., P.M. and Q.C.

\section{Competing interests}

The authors declare no competing interests.

\section{Additional information}

Supplementary Information The online version contains supplementary material available at https://doi.org/ 10.1038/s41598-021-99063-9.

Correspondence and requests for materials should be addressed to G.S. or Q.C.

Reprints and permissions information is available at www.nature.com/reprints.

Publisher's note Springer Nature remains neutral with regard to jurisdictional claims in published maps and institutional affiliations.

(c) (i) Open Access This article is licensed under a Creative Commons Attribution 4.0 International License, which permits use, sharing, adaptation, distribution and reproduction in any medium or format, as long as you give appropriate credit to the original author(s) and the source, provide a link to the Creative Commons licence, and indicate if changes were made. The images or other third party material in this article are included in the article's Creative Commons licence, unless indicated otherwise in a credit line to the material. If material is not included in the article's Creative Commons licence and your intended use is not permitted by statutory regulation or exceeds the permitted use, you will need to obtain permission directly from the copyright holder. To view a copy of this licence, visit http://creativecommons.org/licenses/by/4.0/.

(c) The Author(s) 2021 